CLINICAL STUDY

\title{
Vasoregulatory peptides pro-endothelin-1 and pro-adrenomedullin are associated with metabolic syndrome in the population-based KORA F4 study
}

\author{
Jochen Seissler ${ }^{1,2}$, Nina Feghelm ${ }^{1}$, Cornelia Then ${ }^{1}$, Christa Meisinger ${ }^{3}$, Christian Herder ${ }^{4}$, Wolfgang Koenig ${ }^{5}$, \\ Annette Peters $^{3}$, Michael Roden ${ }^{4,6}$, Andreas Lechner ${ }^{1,2}$, Bernd Kowall ${ }^{7}$ and Wolfgang Rathmann ${ }^{7}$ \\ ${ }^{1}$ Diabetes Zentrum, Medizinische Klinik und Poliklinik IV, Campus Innenstadt, Klinikum der Ludwig-Maximilians-Universität, Ziemssenstraße 1, 80336 \\ München, Germany, ${ }^{2}$ Clinical Cooperation Group Diabetes, Ludwig-Maximilians-Universität München and Helmholtz Zentrum München, München, \\ Germany, ${ }^{3}$ Helmholtz Zentrum München, Institute of Epidemiology II, German Research Center for Environmental Health, Neuherberg, Germany, \\ ${ }^{4}$ German Diabetes Center, Leibniz Institute, Institute for Clinical Diabetology, Heinrich Heine University Düsseldorf, Düsseldorf, Germany, ${ }^{5}$ Department of \\ Internal Medicine II, Cardiology, Medical Center, University of Ulm, Ulm, Germany, ${ }^{6}$ Department of Metabolic Diseases, University Clinics Düsseldorf, \\ Heinrich Heine University, Düsseldorf, Germany and ${ }^{7}$ German Diabetes Center, Leibniz Institute, Institute of Biometrics and Epidemiology, Heinrich Heine \\ University Düsseldorf, Düsseldorf, Germany
}

(Correspondence should be addressed to J Seissler at Diabetes Zentrum, Medizinische Klinik und Poliklinik IV, Campus Innenstadt, Klinikum der Ludwig-Maximilians-Universität; Email: jochen.seissler@med.uni-muenchen.de)

\begin{abstract}
Background: Metabolic alterations and endothelial dysfunction are interrelated processes in type 2 diabetes (T2D) and metabolic syndrome (MetS) that often develop in parallel. We assessed the association of vasoactive precursor peptides (VPPs) with MetS and T2D.

Design and methods: Plasma levels of C-terminal pro-endothelin-1 (CT-proET-1) and midregional proadrenomedullin (MR-proADM) were measured by novel sensitive assays in 1590 participants of the population-based KORA F4 study. The association of the VPPs with T2D, MetS defined by IDF criteria, the components of MetS, and insulin resistance (IR) was assessed in logistic regression models.

Results: Elevated levels of CT-proET-1 and MR-proADM were associated with T2D, MetS, and IR in ageand sex-adjusted models. After adjustment for age, sex, former vascular complications, lifestyle factors, high-sensitive C-reactive protein, and serum creatinine, significant associations with MetS were found for MR-proADM $(\mathrm{OR}=5.94,95 \%$ CI 3.78-9.33) and CT-proET-1 (OR=5.18, 95\% CI 3.48-7.71) (top quartile vs bottom quartile). CT-proET-1 and MR-proADM were strongly associated with all components of MetS as defined by IDF criteria. After multivariable adjustment, association of CT-proET-1 and MR-proADM with pathological glucose tolerance and T2D disappeared and a borderline association with IR was found only for CT-proET-1 (OR=1.34, 95\% CI 0.96-1.87).

Conclusions: We here demonstrate for the first time that plasma levels of both MR-proADM and CT-proET-1 levels are related to MetS and its components, thus suggesting that they possibly have a role as a surrogate biomarker for the disease and its complications.
\end{abstract}

European Journal of Endocrinology $167847-853$

\section{Introduction}

The last decades have seen a dramatic increase in the incidence and prevalence of type 2 diabetes (T2D) and the metabolic syndrome (MetS) (1). Individuals with disturbance of glucose metabolism and/or individuals with MetS are at risk for the premature development of cardiovascular diseases (2). The pathophysiological mechanisms and the interactions between metabolic and vascular alterations in T2D and MetS are not completely understood. A possible link is the dysregulation of vasoactive substances that are involved in both the regulation of endothelial cell function and the glucose metabolism (3). This includes vasoconstrictive acting hormones such as endothelin-1 (ET-1) and vasodilatory peptide adrenomedullin (ADM).
ET-1 is a 21-amino acid peptide secreted by vascular endothelium and represents one of the most potent vasoconstrictors by directly targeting endothelial cells and vascular smooth muscle cells and by inhibition of nitric oxide (NO) formation $(3,4)$. ET-1 is derived from pre-pro-ET that undergoes cleavage by endopeptidases to form inactive precursors pro-ET, which is further cleaved by ET-converting enzyme to the active form. Reliable quantification of this peptide can be made by measuring the $\mathrm{C}$-terminal precursor peptide CT-proET-1, which is more stable and secreted in equimolar concentrations as ET-1. In vivo studies demonstrated that ET-1 is regulated by glucose and induces insulin resistance (IR) $(5,6,7)$. Elevated circulating ET-1 levels were described in patients with 
hypertension, coronary heart disease, congestive heart failure $(\mathrm{CHF})$, and in small cohorts of patients with T2D (7, 8, 9).

An antagonist of ET-1 function is ADM, a 52-amino acid peptide with strong vasodilative properties, which is synthesized by a variety of tissues, including adrenal medulla, vascular endothelial cells, and vascular smooth muscle cells (10). In addition to its hypotensive effects, a variety of biological actions of ADM have been reported including antioxidative and antiapoptotic effects as well as inhibition of insulin secretion in $\beta$-cells $(11,12)$. Using an assay targeting the stable midregional pro-ADM (MR-proADM), it has been shown that increased ADM levels are correlated with CHF, hypertension, and incident cardiovascular events $(9,13,14)$. Thus far, MR-proADM has not been studied in the context of T2D or MetS.

We hypothesized that plasma levels of vasoactive precursor peptides (VPPs) related to vasoconstriction/ inflammation (ET-1) and peptides involved in vasodilation (ADM) may be associated with several components of MetS and/or T2D. Therefore, we aimed to perform an analysis targeting stable prohormones in a populationbased study.

\section{Materials and methods}

\section{Study population}

Data are based on the KORA F4 population study (2006-2008), a follow-up study of the populationbased KORA S4 survey conducted in 1999-2001 in the region of Augsburg, southern Germany. In the KORA F4 study, 3080 subjects were reexamined. The study design, standardized sampling methods, and data collection (medical history, medication, anthropometric measurements, and blood pressure) have been described in detail elsewhere $(15,16)$. All study participants gave written informed consent and the study was approved by the Ethics Committee of the Bavarian Medical Association.

In the current study, we selected a representative sample of 1596 subjects aged 31-81 years. Oral glucose tolerance test (GTT) data were available from 1560 participants and components of MetS can be calculated in 1582 probands. The criteria for prediagnosed diabetes were a validated physician's diagnosis or current use of glucose-lowering agents. After an overnight fasting period of at least $10 \mathrm{~h}$, all nondiabetic participants underwent a standard 75 g OGTT. Newly diagnosed diabetes, impaired glucose tolerance (IGT), impaired fasting glucose (IFG), and normal glucose tolerance (NGT) were defined according to the 1999 World Health Organization diagnostic criteria based on both fasting glucose (FG) and post-challenge glucose values $(\geq 7.0 \mathrm{mmol} / \mathrm{l}$ fasting or $\geq 11.1 \mathrm{mmol} / \mathrm{l}$ 2-h glucose) (17). MetS was defined according to
International Diabetes Federation criteria (18) as visceral obesity (waist circumference $\geq 94 \mathrm{~cm} \mathrm{(men)} \mathrm{and}$ $\geq 80 \mathrm{~cm}$ (women)) and two of the following criteria: FG $\geq 5.6 \mathrm{mmol} / \mathrm{l}$ or diabetes; hypertension (SBP $\geq 130 \mathrm{mmHg}$ and DBP $\geq 85 \mathrm{mmHg}$; or hypertensive drugs); triglycerides $\geq 1.7 \mathrm{mmol} / \mathrm{l}$; high-density lipoprotein (HDL)-cholesterol $<1.0 \mathrm{mmol} / \mathrm{l}$ in men; and $<1.3 \mathrm{mmol} / \mathrm{l}$ in women. Prediabetes was defined as increased fasting plasma glucose $(>5.5 \mathrm{mmol} / \mathrm{l})$ and/or IGT (2-h glucose 7.8-<11.1 mmol/l).

\section{Laboratory measurements}

Blood was collected without stasis and blood was kept at $4{ }^{\circ} \mathrm{C}$ until centrifugation. All blood parameters, except for 2-h glucose, were based on fasting blood samples. Plasma samples were stored at $-80{ }^{\circ} \mathrm{C}$ until assayed and there was only one freeze-thaw cycle before measurements of the VPPs. Blood glucose levels were assessed using the hexokinase method (GLU Flex; Dade Behring). Total cholesterol concentrations, HDL, and low-density lipoprotein (LDL) cholesterol levels were measured according to enzymatic methods (CHOD-PAP; Dade Behring). Triglycerides were measured by an enzymatic color test (GPO-PAP method, TGL Flex; Dade Behring, Marburg, Germany). Serum creatinine concentrations were assessed with a modified Jaffe test (Krea Flex; Dade Behring). HbAlc was measured using the HPLC method. High-sensitivity C-reactive protein (hsCRP) was determined as described previously (17). Glomerular filtration rate was calculated using the MDRD equation (eGFR). Fasting insulin was determined by ELISA (Invitrogen). The IR score (HOMA-IR) was calculated (fasting plasma glucose $(\mathrm{mmol} / \mathrm{l}) \times$ fasting serum insulin (mU/l)/22.5) (19).

Plasma concentrations of stable prohormones, the MR-proADM, and CT-proET-1 were measured by novel sandwich fluoroimmunoassay (BRAHMS, Hennigsdorf, Berlin, Germany) using the automated system BRAHMS KRYPTOR as described in detail elsewhere $(20,21)$. The lower detection limits of these assays were $0.05 \mathrm{nmol} / \mathrm{l}$ for MR-proADM and $2.94 \mathrm{pmol} / \mathrm{l}$ for CT-proET-1. The functional assay sensitivity, defined as the concentration at which the interassay coefficient of variation was $20 \%$, was $0.25 \mathrm{nmol} / \mathrm{l}$ for MR-proADM and $9.78 \mathrm{pmol} / \mathrm{l}$ for CT-proET-1.

\section{Statistical analyses}

Baseline characteristics were compared between subjects with NGT, prediabetes, and T2D. For these comparisons, F-tests were used in case of normally distributed variables. For log-normal variables, F-tests were performed on a log scale. Logistic regression models were used to compare binomial proportions: association between prohormone levels with IFG, IGT, $\mathrm{T} 2 \mathrm{D}$, and components of MetS was adjusted for age and 
sex in crude analysis. Spearman's correlation coefficients were calculated for prohormones.

Multinomial logistic regression models were fitted to assess the association between level of prohormones as independent variable (highest quartile vs lower quartiles) and category of glucose regulation as the dependent variable (NGT, prediabetes, and T2D). Models were adjusted for i) age and sex and ii) age, sex, BMI, hypertension, lipids (HDL-cholesterol, LDL-cholesterol, and triglycerides), former myocardial infarction or stroke, C-reactive protein, creatinine, and lifestyle variables (alcohol consumption, smoking, and physical activity).

In binary logistic regression models, the association between quartiles of prohormones and the presence of MetS was assessed with adjustment for age, sex, former myocardial infarction or stroke, and lifestyle variables. Further logistic regression models with adjustments for the same variables were used to calculate the association between level of prohormones (highest quartile vs lower quartiles) and the presence of single components of the MetS.

Further logistic regression models were fitted with level of prohormones (highest quartile vs lower quartiles) as independent variable and IR (HOMA-IR) as dependent variable with adjustment for age and sex, and adjustment for age, sex, BMI, hypertension, lipids, former myocardial infarction or stroke, and creatinine. We defined IR as HOMA-IR $\geq 75$ th percentile and insulin sensitivity as HOMA-IR $<75$ th percentile.
The level of statistical significance was 5\%. All analyses were performed using the SAS version 9.2 (SAS Institute, Cary, NC, USA).

\section{Results}

\section{Clinical characteristics and correlation between VPPs}

Baseline characteristics of the study groups are given in Table 1. The mean age of the study population was $56.9 \pm 12.9$ years. Of all the study participants, $70.5 \%$ exhibited a NGT, $17.8 \%$ had IFG or IGT, and $11.7 \%$ were diabetic. According to IDF criteria, 33.3\% of the study population had MetS. Crude levels of CT-proET-1 and MR-proADM were highest in individuals with T2D compared with IGT/IFG and NGT (Fig. 1). Both VPPs were positively associated with BMI, age, LDL-cholesterol levels, triglyceride levels and hsCRP, and negatively associated with HDL-cholesterol levels and glomerular filtration rate.

\section{Association of biomarkers with different categories of glucose tolerance}

After adjustment for age and sex, prevalence of T2D and IGT/IFG of disturbed glucose tolerance were higher for subjects with increased plasma levels of CT-proET-1 and

Table 1 Baseline characteristics of study participants according to categories of glucose tolerance ${ }^{\mathrm{a}}$. Analyses were adjusted for age and sex.

\begin{tabular}{|c|c|c|c|c|}
\hline & NGT & Prediabetes & T2DM & $\boldsymbol{P}$ \\
\hline$n$ & 1100 & 277 & 183 & \\
\hline Age (years) & $53.5 \pm 12.4$ & $63.8 \pm 10.8$ & $66.4 \pm 9.1$ & $<0.001^{b}$ \\
\hline Sex (male; \%) & 46.1 & 53.8 & 57.9 & $0.01^{\mathrm{c}}$ \\
\hline BMI $\left(\mathrm{kg} / \mathrm{m}^{2}\right)$ & $26.4 \pm 4.2$ & $29.3 \pm 4.6$ & $30.9 \pm 4.6$ & $<0.001^{b}$ \\
\hline Waist (cm) & $90.1 \pm 12.9$ & $99.4 \pm 12.4$ & $104.4 \pm 11.6$ & $<0.001^{b}$ \\
\hline $\mathrm{FPG}(\mathrm{mmol} / \mathrm{l})$ & $5.1 \pm 0.4$ & $5.7 \pm 0.6$ & $7.3 \pm 1.9$ & $<0.001^{b}$ \\
\hline 2-h glucose $(\mathrm{mmol} / \mathrm{l})$ & $5.5 \pm 1.1$ & $8.5 \pm 1.4$ & - & $<0.001^{b}$ \\
\hline Hypertension ${ }^{\mathrm{d}}(\%)$ & 28.9 & 58.1 & 79.8 & $<0.001^{\mathrm{c}}$ \\
\hline HDL-cholesterol (mmol/l) & $1.50 \pm 0.38$ & $1.39 \pm 0.35$ & $1.27 \pm 0.29$ & $<0.001^{b}$ \\
\hline LDL-cholesterol $(\mathrm{mmol} / \mathrm{l})$ & $3.48 \pm 0.87$ & $3.75 \pm 0.93$ & $3.27 \pm 0.84$ & $<0.001^{\mathrm{b}}$ \\
\hline Triglycerides $(\mathrm{mmol} / \mathrm{l})$ & $1.07(0.74,1.55)$ & $1.42(1.06,1.95)$ & $1.50(1.06,2.33)$ & $<0.001^{\mathrm{e}}$ \\
\hline $\operatorname{hsCRP}(\mathrm{mg} / \mathrm{l})$ & $0.93(0.46,1.96)$ & $1.60(0.88,3.45)$ & $1.88(0.92,4.36)$ & $<0.001^{\mathrm{e}}$ \\
\hline Creatinine (mg/dl) & $0.89 \pm 0.20$ & $0.92 \pm 0.20$ & $1.00 \pm 0.26$ & $<0.001^{b}$ \\
\hline Former stroke or $\mathrm{Ml}(\%)$ & 3.7 & 5.8 & $15.3^{-0.2}$ & $0.007^{\mathrm{c}}$ \\
\hline Active smoker (\%) & 20.2 & 10.1 & 12.0 & $0.13^{\mathrm{c}}$ \\
\hline Former smoker (\%) & 37.4 & 40.8 & 45.9 & $0.74^{\mathrm{c}}$ \\
\hline High alcohol consumption ${ }^{f}(\%)$ & 19.7 & 18.1 & 16.9 & $0.81^{\mathrm{c}}$ \\
\hline No alcohol consumption (\%) & 26.8 & 29.6 & 36.6 & $0.02^{c}$ \\
\hline Physically inactive (\%) & 37.8 & 50.2 & 57.4 & $<0.001^{c}$ \\
\hline MR-proADM (nmol/l) & $0.47(0.40,0.55)$ & $0.56(0.49,0.67)$ & $0.64(0.53,0.77)$ & $<0.001^{\mathrm{e}}$ \\
\hline CT-proET-1 (pmol//) & $43.4(37.9,49.9)$ & $49.8(43.2,57.2)$ & $56.0(47.6,66.9)$ & $<0.001^{\mathrm{e}}$ \\
\hline Insulin $(\mu \mathrm{IU} / \mathrm{ml})$ & $3.7(2.5,5.9)$ & $6.1(3.9,12.5)$ & $7.3(4.0,17.7)$ & $<0.001^{\mathrm{e}}$ \\
\hline
\end{tabular}

NGT, normal glucose tolerance; T2DM, type 2 diabetes mellitus; FPG, fasting plasma glucose; MI, myocardial infarction; hsCRP, high-sensitive C-reactive protein (serum).

${ }^{\mathrm{a}}$ Mean \pm s.D., median (25th and 75th percentiles), and proportions (\%).

${ }^{\mathrm{b}}$ F-test.

'Logistic regression (comparison between NGT, prediabetes, and T2DM).

dBlood pressure of $140 / 90 \mathrm{mmHg}$ or higher or antihypertensive medication.

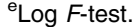

fHigh alcohol intake, $\geq 40 \mathrm{~g} /$ day in men and $\geq 20 \mathrm{~g} /$ day in women. 

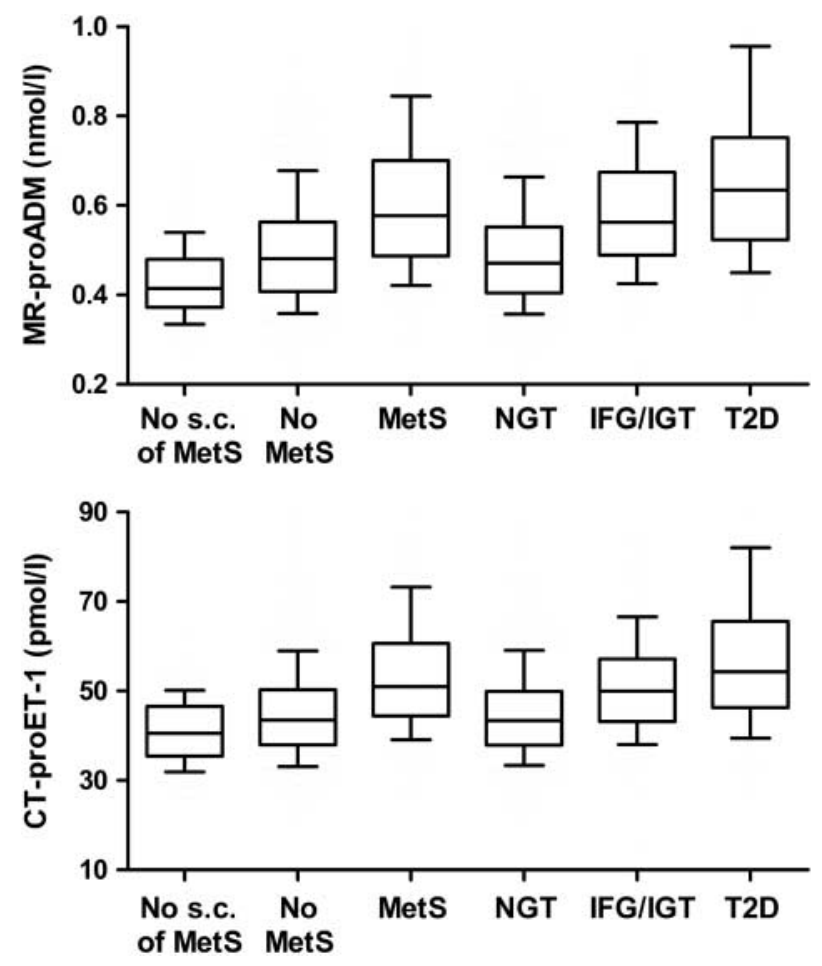

Figure 1 Boxplots (median, interquartile range, and 10-90th percentile) of MR-proADM and CT-proET-1 plasma levels according to glucose tolerance status and the presence of components of metabolic syndrome (MetS). s.c., single component of MetS NGT, normal glucose tolerance; IFG, impaired fasting glucose; IGT, impaired glucose tolerance, T2D, type 2 diabetes.

MR-proADM (highest quartile of VPPs vs lower quartiles; Table 2). Multivariable adjustment for age, sex, BMI, hypertension, HDL-cholesterol, LDL-cholesterol, triglycerides, vascular complications, smoking, alcohol consumption, physical activity, hsCRP, and serum creatinine attenuated these associations. Associations between MR-proADM and CT-proET-1 and prediabetes as well as diabetes were no longer significant after multiple adjustments for all covariates. The major influence on the relationship between prohormones and prediabetes as well as T2D was mediated by obesity (BMI and waist circumference). Both MR-proADM $(\mathrm{OR}=2.50,95 \%$ CI $1.86-3.37)$ and CT-proET-1 $(\mathrm{OR}=2.79,95 \%$ CI $2.12-3.68)$ were correlated with IR measured by HOMA-IR after adjustment for age and sex. After further multivariable adjustment, a borderline association with IR was only seen in CT-proET-1 (OR $=1.34,95 \%$ CI $0.96-1.87)$.

\section{Relationship between CT-proET-1 and MR-proADM and the MetS}

Mean levels of CT-proET-1 $(54.3 \pm 15.0$ vs 44.8 $\pm 12.5 \mathrm{pmol} / \mathrm{l})$ and MR-proADM $(0.62 \pm 0.19$ vs $0.49 \pm 0.14 \mathrm{nmol} / \mathrm{l}$ ) were higher in patients with MetS than in those who had no MetS and in subjects without the presence of any component of MetS $(P<0.001$; Fig. 1). CT-proET-1 $(\mathrm{OR}=5.18,95 \% \mathrm{CI}$ 3.48-7.71) and MR-proADM $(\mathrm{OR}=5.94,95 \%$ CI 3.78-9.33) were independent significant markers for MetS when the top quartile (Q4) of the VPPs was compared with the bottom quartile (Q1) (Table 3). To examine the impact of abdominal obesity, higher triglyceride levels, low HDL-cholesterol levels, hypertension, and disturbance of glucose metabolisms, we conducted further analyses of single components of MetS. Adjusted ORs for single components of MetS with biomarkers are shown in Table 4. CT-proET-1 and MR-proADM plasma levels were strongly related to all components defining MetS. These associations were present in young (age 31-60 years) and older subjects (age $\geq 61$ years).

\section{Discussion}

In this study, we have examined for the first time the association between vasoregulatory polypeptide hormones ET-1 and ADM with T2D and MetS in a population-based study. The key finding of our study is that there is a strong relation of MR-proADM and CT-proET-1 with multiple variables of MetS, whereas both polypeptides were not independent markers of prediabetes or overt T2D.

So far, only a few studies reported on the correlation between vasoactive substances and T2D or MetS $(7,8)$. Until recently, measurement of vasoactive polypeptides was extremely difficult because of the rapid degradation with a plasma halftime of a few minutes. In this study, we chose novel assays targeting stable prohomones for direct comparison of their association with MetS and T2D.

This is the first population-based study on a combined analysis of plasma proET-1 and proADM levels. We here show that after adjustment for conventional risk factors ET-1 and ADM, two opposingly acting hormones were significantly elevated in patients with MetS. Increased

Table 2 Adjusted ORs $(95 \% \mathrm{Cl})$ for glucose regulation (T2D, prediabetes, and NGT (reference)) as dependent variable and categories of prohormones as independent variables (highest quartile Q4 vs lower quartiles Q1-Q3 (reference)): results of multinomial logistic regression models.

\begin{tabular}{lll}
\hline Adjustment & Prediabetes & Type 2 diabetes \\
\hline MR-proADM $(\mathrm{nmol} / \mathrm{l})$ & & \\
Age, sex & $\mathbf{1 . 5 2}(\mathbf{1 . 0 8 - 2 . 1 3 )}$ & $\mathbf{3 . 6 4}(\mathbf{2 . 4 6 - 5 . 3 9 )}$ \\
Multivariate $^{\mathrm{a}}$ & $1.09(0.74-1.62)$ & $1.51(0.94-2.42)$ \\
CT-proET-1 $(\mathrm{pmol} / \mathrm{l})$ & & \\
Age, sex $^{\mathrm{M}}$ & $\mathbf{1 . 4 6 ( 1 . 0 5 - 2 . 0 1 )}$ & $\mathbf{2 . 8 8}(1.99-4.16)$ \\
Multivariate $^{\mathrm{a}}$ & $1.04(0.72-1.51)$ & $1.10(0.70-1.72)$ \\
\hline
\end{tabular}

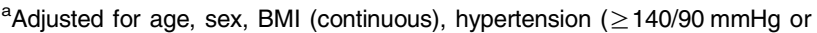
antihypertensive medicine), HDL-cholesterol (continuous), LDL-cholesterol (continuous), triglycerides (continuous), former myocardial infarction or stroke, smoking (active/former/never), alcohol consumption (abstinent/moderate/high), physical activity (high/low), hsCRP (continuous), and creatinine (continuous). The OR values are highlighted in boldface because they are significant. 
Table 3 Adjusted ORs $(95 \% \mathrm{Cl}$ ) for the metabolic syndrome (defined by IDF criteria) as dependent variable and categories of CT-proET-1 and MR-proADM as independent variables: results of logistic regression models ${ }^{\mathrm{a}}(n=1581)$.

\begin{tabular}{lcccc}
\hline & Q4 vs Q1 & Q3 vs Q1 & Q2 vs Q1 & Q4 vs Q1-3 \\
\hline MR-proADM (nmol/l) & $5.94(3.78-9.33)$ & $2.99(1.99-4.48)$ & $2.40(1.61-3.57)$ & $2.38(1.78-3.19)$ \\
CT-proET-1 (pmol/l) & $5.18(3.48-7.71)$ & $2.88(1.96-4.21)$ & $2.25(1.53-3.30)$ & $2.42(1.84-3.17)$ \\
\hline
\end{tabular}

Q4 highest quartile, Q1 lowest quartile (reference); MR-proADM, Q1 <0.43; Q2 0.43-0.51; Q3 0.52-0.61; Q4 >0.61 nmol/l. CT-proET-1, Q1 <39.4; Q2 39.4-45.57; Q3 45.58-53.42; Q4 > 53.42.

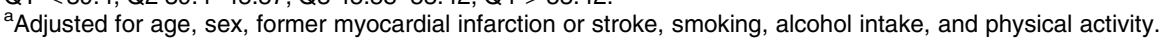

CT-proET-1 and MR-proADM levels were significantly associated with central obesity, lipid disorders (raised triglycerides and reduced HDL-cholesterol), and hypertension. The correlation between circulating ET-1 and hypertension and endothelial dysfunction is well known from previous studies $(3,22)$. As ET-1 is known to activate several signaling pathways involved in proatherogenic cellular events (23), risk for premature atherosclerosis in subjects with MetS could be a direct consequence of increased ET-1 plasma levels. ET-1 measurement in diabetes mellitus yielded inconsistent results. While some studies observed higher ET-1 levels $(8,24)$, other studies reported normal ET-1 concentrations in diabetic patients $(22,25)$. Our data extend current knowledge to a large group of subjects demonstrating that plasma proET-1 levels are elevated in individuals with increased IR as assessed by HOMA-IR, subjects at risk for T2D, and in diabetic patients. However, this was attenuated to nonsignificant levels after multivariable logistic regression analysis including conventional risk factors, suggesting that some differences in previous studies may be explained by the small number of participants, the duration of diabetes, the adjustment for fewer confounders, or potential methodological problems with the older ET-1 assays $(8,20)$.

So far, circulating ADM levels were only investigated in small cohorts of diabetic patients with inconsistent results $(26,27,28)$. In line with our findings, Lim et al. (29) reported increased MR-proADM levels in patients with T2D, which were related to chronic inflammation (hsCRP), lipids, and IR. We are the first to demonstrate that MR-proADM levels are highly correlated with
MetS, suggesting that ADM may play a role in the pathogenesis of this disorder. The observed strong relation between plasma levels of CT-proET-1 and MR-proADM suggests an interconnection between both polypeptide hormones. ET-1 is thought to be a key mediator in the pathogenesis of hypertension, macrovascular diseases, and diabetic microangiopathy, whereas ADM acts through vasodilation, natriuresis, and NO production $(4,23)$. There is evidence from in vitro studies that ET-1 stimulates interleukin 6 secretion and downregulates adiponectin expression (30). In addition, ET-1 may further predispose to a proinflammatory state by increasing inflammatory mediators such as tumor necrosis factor- $\alpha$ and monocyte chemotactic protein-1 known to be involved in the development of metabolic disorders $(31,32,33)$. ET-1 also has an impact on adipocyte physiology by inhibition of adipocyte differentiation and insulinstimulated glucose uptake, inhibition of glucose uptake in the skeletal muscle, and by stimulation of lipolysis and hepatic glycogenolysis favoring the development of IR and metabolic disorders $(5,6,34,35)$. On the other hand, ADM secreted by adipocytes may act against the proinflammatory micromilieu through its antioxidant actions (10). High ADM can inhibit insulin secretion (11) and may thereby contribute to the development of glucose intolerance. According to the findings of many clinical trials reporting on early vascular dysfunction in patients with MetS and prediabetes (2), it is tempting to speculate that during the development of MetS, vasoconstrictive substances may be activated. Endothelial-derived ADM may be upregulated in response to the increased vascular tonus and/or ongoing vascular

Table 4 Adjusted ORs $(95 \% \mathrm{Cl}$ ) for single components of the metabolic syndrome (defined by IDF criteria) as dependent variables and categories of CT-proET-1 and MR-proADM as independent variables (Q4 vs Q1-Q3 (reference)): results of logistic regression models ${ }^{\mathrm{a}}$ $(n=1581)$.

\begin{tabular}{|c|c|c|c|c|c|}
\hline & Central obesity ${ }^{b}$ & $\begin{array}{c}\text { Raised } \\
\text { triglyceride level }^{\mathrm{c}}\end{array}$ & $\begin{array}{c}\text { Reduced } \\
\text { HDL-cholesterol }^{\mathrm{d}}\end{array}$ & Hypertension $^{\mathrm{e}}$ & $\begin{array}{l}\text { Raised FPG or } \\
\text { known diabetes }\end{array}$ \\
\hline $\begin{array}{l}\text { MR-proADM }(\mathrm{nmol} / \mathrm{l}) \\
\text { CT-proET-1 }(\mathrm{pmol} / \mathrm{l})\end{array}$ & $\begin{array}{l}3.45(2.32-5.12) \\
2.48(175-3.49)\end{array}$ & $\begin{array}{l}1.76(1.29-2.41) \\
277(2.08-370)\end{array}$ & $2.36(1.65-3.37)$ & $2.19(1.59-3.02)$ & $1.71(1.27-2.29)$ \\
\hline
\end{tabular}

Q4, highest quartile.

${ }^{a}$ Adjusted for age, sex, former myocardial infarction/stroke, smoking, alcohol intake, and physical activity.

befined as $\geq 94 \mathrm{~cm}$ for men and $\geq 80 \mathrm{~cm}$ for women.

${ }^{c}$ Defined as $\geq 1.7 \mathrm{mmol} / \mathrm{l}$.

dDefined as $<1.0 \mathrm{mmol} / \mathrm{l}$ for men and $<1.3 \mathrm{mmol} / \mathrm{l}$ for women.

e Defined as systolic blood pressure $\geq 130 \mathrm{mgHg}$, diastolic blood pressure $\geq 85 \mathrm{mgHg}$, or treatment of previously diagnosed hypertension

fDefined as fasting plasma glucose (FPG) as $\geq 5.5 \mathrm{mmol} / /$ or previously diagnosed T2D. 
injury with consecutive disturbance of microvascular homeostasis. This could be one explanation for why both prohormones were found to be elevated in patients with MetS in this study. However, this hypothesis needs to be confirmed in further clinical studies.

A strength of our study is the simultaneous assessment of two VPPs in a large population-based study. We provide the first data on the correlation of CT-proET-1 and MR-proADM with T2D/MetS in a large cohort using novel analytical techniques. In addition to anthropometric measurements and clinical covariates, a $75 \mathrm{~g}$ OGTT was available from all nondiabetic individuals. This excludes the possibility of undiagnosed glucose intolerance in subjects classified as NGT. Several studies have described a correlation between high VVP levels and cardiovascular complications and mortality $(9,13,14,36,37)$. The limitation of our study is that we have only cross-sectional data. Therefore, we are not able to make any causal statements on the interaction of VPPs and development of diabetes, MetS, or vascular complications.

In conclusion, our study demonstrated a strong link between peptides modulating the activation of endothelial cells and MetS. Subjects with plasma levels of CT-proET-1 or MR-proADM in the upper quartile had an OR of more than 5 for having MetS compared with individuals with low-level VPPs. These findings raise the possibility that increased VVPs are surrogate biomarkers for MetS, which may have important clinical and pathophysiological implications. Further prospective clinical trials are required to examine whether the alteration of vasoactive substances is involved in the pathogenesis of MetS, T2D, or vascular complications.

\section{Declaration of interest}

The authors declare that there is no conflict of interest that could be perceived as prejudicing the impartiality of the research reported.

\section{Funding}

The KORA research platform studies were initiated and financed by the Helmholtz Zentrum München - National Research Center for Environmental Health, which is funded by the German Federal Ministry of Education, Science, Research and Technology, and by the State of Bavaria. The study was supported by a research grant from the Virtual Diabetes Institute (Helmholtz Zentrum München) and the Clinical Cooperation Group Diabetes, Ludwig-Maximilians-University München, and Helmholtz Zentrum Muenchen. Further support was obtained from the Federal Ministry of Health and the Ministry of Innovation, Science, Research and Technology of the state North Rhine Westphalia. Measurement of vasoactive polypeptides was funded by a grant of the Karl-Wilder Foundation (J Seissler).

\section{Author contribution statement}

J Seissler, N Feghelm, C Then, A Lechner, C Meisinger, A Peters, W Koenig, B Kowall, and $W$ Rathmann were involved in the conception and design of the study; J Seissler, N Feghelm, C Then, C Meisinger, C Herder, A Peters, W Koenig, and W Rathmann were involved in the collection of data; B Kowall and W Rathmann contributed to data analysis; and J Seissler, C Then, A Lechner, C Meisinger, C Herder, W Koenig, A Peters, M Roden, B Kowall, and W Rathmann were involved in the interpretation of results and writing of the manuscript.

\section{Acknowledgements}

The KORA study group consists of H-E Wichmann (speaker), R Holle, J John, T Illig, C Meisinger, A Peters, and their coworkers, who are responsible for the design and conduct of the KORA studies. The authors gratefully acknowledge the contribution of all members of field staff conducting the KORA F4 study and thank all study probands participating in the study.

\section{References}

1 Zimmet P, Magliano D, Matsuzawa Y, Alberti G \& Shaw J. The metabolic syndrome: a global public health problem and a new definition. Journal of Atherosclerosis and Thrombosis 200512 295-300. (doi:10.5551/jat.12.295)

2 Clough G, Krentz AJ \& Byrne CD. Vascular disease in the metabolic syndrome: do we need to target the microcirculation to treat large vessel disease? Journal of Vascular Research 200946 515-526. (doi:10.1159/000176041)

3 Tesauro M \& Cardillo C. Obesity, blood vessels and metabolic syndrome. Acta Physiologica 2011203 279-286. (doi:10.1111/j. 1748-1716.2011.02290.x)

4 Thorin E \& Webb DJ. Endothelium-derived endothelin-1. Pflügers Archiv: European Journal of Physiology $2010 \quad 459$ 951-958. (doi:10.1007/s00424-009-0763-y)

5 Ottosson-Seeberger A, Lundberg JM, Alvestrand A \& Ahlborg G. Exogenous endothelin-1 causes peripheral insulin resistance in healthy humans. Acta Physiologica Scandinavica $1997 \mathbf{1 6 1}$ 211-220. (doi:10.1046/j.1365-201X.1997.00212.x)

6 Lee YC, Juan CC, Fang VS, Hsu YP, Lin SH, Kwok CF \& Ho LT. Evidence that endothelin-1 (ET-1) inhibits insulin-stimulated glucose uptake in rat adipocytes mainly through ETA receptors. Metabolism $1998 \quad 47$ 1468-1471. (doi:10.1016/S0026-0495 (98)90071-3)

7 DeLoach S, Huan Y, Daskalakis C \& Falkner B. Endothelin-1 response to glucose and insulin among African Americans. Journal of the American Society of Hypertension 2010 4 227-235. (doi:10.1016/j.jash.2010.07.004)

8 Ak G, Buyukberber S, Sevinc A, Turk HM, Ates M, Sari R, Savli H \& Cigli A. The relation between plasma endothelin-1 levels and metabolic control, risk factors, treatment modalities, and diabetic microangiopathy in patients with type 2 diabetes mellitus. Journal of Diabetes and its Complications 20015 150-157. (doi:10.1016/S1056-8727(01)00137-4)

9 Behnes M, Papassotiriou J, Walter T, Fiedler E, Sauer T, Lang S, Elmas E, Hoffmann U, Borggrefe M \& Brueckmann M. Long-term prognostic value of mid-regional pro-adrenomedullin and C-terminal pro-endothelin-1 in patients with acute myocardial infarction. Clinical Chemistry and Laboratory Medicine 200846 204-211. (doi:10.1515/CCLM.2008.040)

10 Kato J, Tsuruda T, Kita T, Kitamura K \& Eto T. Adrenomedullin: a protective factor for blood vessels. Arteriosclerosis, Thrombosis, and Vascular Biology 200525 2480-2487. (doi:10.1161/01.ATV. 0000184759.91369.f8)

11 Zudaire E, Cuttitta F \& Martínez A. Regulation of pancreatic physiology by adrenomedullin and its binding protein. Regulatory Peptides 2003112 121-130. (doi:10.1016/S0167-0115(03) 00030-2)

12 Li Y, Jiang C, Wang X, Zhang Y, Shibahara S \& Takahashi K. Adrenomedullin is a novel adipokine: adrenomedullin in adipocytes and adipose tissues. Peptides 200728 1129-1143. (doi:10. 1016/j.peptides.2007.03.005) 
13 Melander O, Newton-Cheh C, Almgren P, Hedblad B, Berglund G, Engström G, Persson M, Smith JG, Magnusson M, Christensson A, Struck J, Morgenthaler NG, Bergmann A, Pencina MJ \& Wang TJ. Novel and conventional biomarkers for prediction of incident cardiovascular events in the community. Journal of the American Medical Association 2009302 49-57. (doi:10.1001/jama.2009. 943)

14 Masson S, Latini R, Carbonieri E, Moretti L, Rossi MG, Ciricugno S, Milani V, Marchioli R, Struck J, Bergmann A, Maggioni AP, Tognoni G, Tavazzi L \& GISSI-HF Investigators. The predictive value of stable precursor fragments of vasoactive peptides in patients with chronic heart failure: data from the GISSI-heart failure (GISSI-HF) trial. European Journal of Heart Failure 201012 338-347. (doi:10.1093/eurjhf/hfp206)

15 Meisinger C, Rückert IM, Rathmann W, Döring A, Thorand B, Huth C, Kowall B \& Koenig W. Retinol-binding protein 4 is associated with prediabetes in adults from the general population: the Cooperative Health Research in the region of Augsburg (KORA) F4 Study. Diabetes Care 201134 1648-1650. (doi:10. 2337/dc11-0118)

16 Rathmann W, Strassburger K, Heier M, Holle R, Thorand B, Giani G, Peters A \& Meisinger C. Incidence of type 2 diabetes in the older German population and the effect of clinical and lifestyle risk factors: KORA S4/F4 cohort study. Diabetic Medicine 200926 1212-1219. (doi:10.1111/j.1464-5491.2009.02863.x)

17 Rathmann W, Haastert B, Icks A, Löwel H, Meisinger C, Holle R \& Giani G. High prevalence of undiagnosed diabetes mellitus in southern Germany: target populations for efficient screening. The KORA survey 2000. Diabetologia $2003 \quad 46$ 182-189. (doi:10.1007/s00125-002-1025-0)

18 Alberti KG, Eckel RH, Grundy SM, Zimmet PZ, Cleeman JI, Donato KA, Fruchart JC, James WP, Loria CM \& Smith SC Jr. Harmonizing the metabolic syndrome: a joint interim statement of the International Diabetes Federation Task Force on Epidemiology and Prevention; National Heart, Lung, and Blood Institute; American Heart Association; World Heart Federation; International Atherosclerosis Society; and International Association for the Study of Obesity. Circulation 20092 1640-1645. (doi:10. 1161/CIRCULATIONAHA.109.192644)

19 Rathmann W, Haastert B, Herder C, Hauner H, Koenig W, Meisinger C, Holle R \& Giani G. Differential association of adiponectin with cardiovascular risk markers in men and women? The KORA survey. International Journal of Obesity 2007 31 770-776. (doi:10.1038/sj.ijo.0803471)

20 Papassotiriou J, Morgenthaler NG, Struck J, Alonso C \& Bergmann A. Immunoluminometric assay for measurement of the C-terminal endothelin-1 precursor fragment in human plasma. Clinical Chemistry 200652 1144-1151. (doi:10.1373/ clinchem.2005.065581)

21 Caruhel P, Mazier C, Kunde J, Morgenthaler NG \& Darbouret B. Homogeneous time-resolved fluoroimmunoassay for the measurement of midregional proadrenomedullin in plasma on the fully automated system B.R.A.H.M.S KRYPTOR. Clinical Biochemistry 200942 725-728. (doi:10.1016/j.clinbiochem.2009.01.002)

22 Perassolo MS, Almeida JC, Steemburgo T, Dall'Alba V, de Mello VD, Zelmanovitz T, de Azevedo MJ \& Gross JL. Endothelial dysfunction and serum fatty acid composition in patients with type 2 diabetes mellitus. Metabolism 200857 1167-1172. (doi:10.1016/j. metabol.2008.01.006)

23 Little PJ, Ivey ME \& Osman N. Endothelin-1 actions on vascular smooth muscle cell functions as a target for the prevention of atherosclerosis. Current Vascular Pharmacology 20086 195-203. (doi:10.2174/157016108784911966)
24 Seligman BG, Biolo A, Polanczyk CA, Gross JL \& Clausell N. Increased plasma levels of endothelin 1 and von Willebrand factor in patients with type 2 diabetes and dyslipidemia. Diabetes Care 200023 1395-1400. (doi:10.2337/diacare.23.9.1395)

25 Güvener N, Aytemir K, Aksöyek S \& Gedik O. Plasma endothelin-1 levels in non-insulin dependent diabetes mellitus patients with macrovascular disease. Coronary Artery Disease 19978 253-258. (doi:10.1097/00019501-199705000-00001)

26 Hayashi M, Shimosawa T, Isaka M, Yamada S, Fujita R \& Fujita T. Plasma adrenomedullin in diabetes. Lancet $1997 \mathbf{3 5 0}$ 1449-1450. (doi:10.1016/S0140-6736(05)64211-0)

27 Kinoshita H, Kato K, Kuroki M, Nakamura S, Kitamura K, Hisanaga S, Fujimoto S \& Eto T. Plasma adrenomedullin levels in patients with diabetes. Diabetes Care 200023 253-254. (doi:10. 2337/diacare.23.2.253)

28 Ruzicska E, Toth M, Tulassay Z \& Somogyi A. Adrenomedullin and diabetes mellitus. Diabetes/Metabolism Research and Reviews 2001 17 321-329. (doi:10.1002/dmrr.223)

29 Lim SC, Morgenthaler NG, Subramaniam T, Wu YS, Goh SK \& Sum CF. The relationship between adrenomedullin, metabolic factors, and vascular function in individuals with type 2 diabetes. Diabetes Care 200730 1513-1519. (doi:10.2337/dc06-1899)

30 Juan CC, Chuang TY, Chang CL, Huang SW \& Ho LT. Endothelin-1 regulates adiponectin gene expression and secretion in 3T3-L1 adipocytes via distinct signaling pathways. Endocrinology 2007 148 1835-1842. (doi:10.1210/en.2006-0654)

31 Herder C, Baumert J, Thorand B, Koenig W, de Jager W, Meisinger C, Illig T, Martin S \& Kolb $\mathrm{H}$. Chemokines as risk factors for type 2 diabetes: results from the MONICA/KORA Augsburg study, 1984-2002. Diabetologia 200649 921-929. (doi:10.1007/s00125-006-0190-y)

32 Simonson MS \& Ismail-Beigi F. Endothelin-1 increases collagen accumulation in renal mesangial cells by stimulating a chemokine and cytokine autocrine signaling loop. Journal of Biological Chemistry 2011286 11003-11008. (doi:10.1074/jbc.M110.190793)

33 Zarpelon AC, Pinto LG, Cunha TM, Vieira SM, Carregaro V, Souza GR, Silva JS, Ferreira SH, Cunha FQ \& Verri WA Jr. Endothelin-1 induces neutrophil recruitment in adaptive inflammation via TNF $\alpha$ and CXCL1/CXCR2 in mice. Canadian Journal of Physiology and Pharmacology 201290 187-199. (doi:10.1139/ y11-116)

34 Roden M, Vierhapper H, Liener K \& Waldhäusl W. Endothelin-1stimulated glucose production in vitro in the isolated perfused rat liver. Metabolism $1992 \mathbf{4 1}$ 290-295. (doi:10.1016/00260495(92)90273-D)

35 Shemyakin A, Salehzadeh F, Esteves Duque-Guimaraes D, Böhm F, Rullman E, Gustafsson T, Pernow J \& Krook A. Endothelin-1 reduces glucose uptake in human skeletal muscle in vivo and in vitro. Diabetes 201160 2061-2067. (doi:10.2337/db10-1281)

36 Maier C, Clodi M, Neuhold S, Resl M, Elhenicky M, Prager R, Moertl D, Strunk G, Luger A, Struck J, Pacher R \& Hülsmann M. Endothelial markers may link kidney function to cardiovascular events in type 2 diabetes. Diabetes Care 200932 1890-1895. (doi:10.2337/dc08-2168)

37 Volpe M, Francia P, Tocci G, Rubattu S, Cangianiello S, Elena Rao MA, Trimarco B \& Condorelli M. Prediction of long-term survival in chronic heart failure by multiple biomarker assessment: a 15-year prospective follow-up study. Clinical Cardiology 201033 700-707. (doi:10.1002/clc.20813)

Received 31 May 2012

Revised version received 17 September 2012

Accepted 20 September 2012 